\title{
Prevalence and correlates of sexual intercourse among sexually active in-school adolescents: an analysis of five sub-Sahara African countries for the adolescent's sexual health policy implications
}

Festo K. Shayo ${ }^{1,2^{*}}$ id and Mariam H. Kalomo ${ }^{3}$

\begin{abstract}
Background: Early and unprotected sex with multiple partners among adolescents carries a high risk of acquiring HIV infections, other sexually transmitted infections as well as high rates of teenage pregnancy. Sub-Saharan Africa (SSA) has a higher burden of HIV/AIDS: the leading cause of deaths among adolescents. We estimated the prevalence and examined the correlates of sexual intercourse among in-school adolescents of SSA. The purpose is to inform the public health programs dedicated to tackling the burden of HIV/AIDS.
\end{abstract}

Methods: We did a secondary analysis of the Global School-based Student Health Surveys (GSHS) datasets pooled from five SSA countries Benin, Mozambique, Namibia, Seychelles, and Tanzania. Our current analysis included a sample of 15,318 in-school adolescents. The primary independent variables were ever had sexual intercourse and sex with multiple partners, while the dependent variables were smoking cigarettes, alcohol use, use of marijuana and amphetamine, and parental connectedness. We performed descriptive statistics, and multivariate logistic regression stratified by gender using SPSS Complex Sample Statistics. A p-value of less than 0.05 was considered statistically significant at $95 \%$ confidence intervals.

Results: Out of 15,318 participants, the overall prevalence of ever had sexual intercourse and sex with multiple partners were $43.5 \%$ (6670) and 20.9\% (3204), respectively. In overall and across each country, male adolescents had a significantly higher proportion of sex with multiple partners than female adolescents, $p<0.001$. The predictors of sexual intercourse with multiple partners in both male and females were smoking cigarettes, alcohol use, and use of marijuana and amphetamine. Female adolescents who smoked cigarettes and used marijuana had a significant likelihood of sex with multiple partners than male adolescents: [aOR 3.6, 95\% Cl: 2.6-5.1] vs [aOR 2.1, 95\% Cl: 1.7-2.7] and [aOR 2.4, 95\% Cl: 1.6-3.7] vs [aOR 1.9, 95\% Cl: 1-3-2.7], respectively.

Conclusions: Adolescents sexual intercourse and more especially sex with multiple partners was prevalent and strongly correlated with substance use. However, the correlation was higher among female adolescents than male adolescents. A customized public health intervention that targets multiple risk factors concurrently may benefit adolescents with clustering of sexual and non-sexual risk-taking behaviors.

Keywords: Adolescents, Sexual intercourse, Substance use, Parental connectedness, HIV/AIDS, Sub-Saharan Africa

\footnotetext{
* Correspondence: festocasmir@gmail.com

'Department of Internal Medicine, Muhimbili University of Health and Allied

Sciences, P.O Box 65001, Dar es Salaam, Tanzania

2Division of Public Health, Department of Global Health Entrepreneurship,

Graduate School of Tokyo Medical and Dental University, 1-5-45 Yushima,

Bunkyo-ku, Tokyo 113-8510, Japan

Full list of author information is available at the end of the article
}

(c) The Author(s). 2019 Open Access This article is distributed under the terms of the Creative Commons Attribution 4.0 International License (http://creativecommons.org/licenses/by/4.0/), which permits unrestricted use, distribution, and reproduction in any medium, provided you give appropriate credit to the original author(s) and the source, provide a link to the Creative Commons license, and indicate if changes were made. The Creative Commons Public Domain Dedication waiver (http://creativecommons.org/publicdomain/zero/1.0/) applies to the data made available in this article, unless otherwise stated. 


\section{Background}

Adolescence period has different critical transitions such as physical, economic, and psychosocial development. Moreover, it is a preferred period for initiating sexual and reproductive health promotion programs [1]. Adolescence sexuality is among the risk-taking behaviors in this age group [2]. The immaturity of the prefrontal cortex in adolescents is associated with heightened impulsivity and inability to have a wise plan or forecast the consequences of risk-taking behaviors [3] such as sexual intercourse. Early age at sexual intercourse is a strong predictor of future poor sexual health, including other health-related risk behaviors among adolescents [3-5]. Sexual intercourse in adolescence increases the risk of acquiring HIV infections, sexually transmitted infections (STIs) [5-7], and unintended teenage pregnancy [7-9]. Moreover, it is associated with unprotected sexual intercourse [10], having multiple sexual partners and other health-related risks behaviors, later in life $[5,8,11]$. In SSA, up to $25 \%$ of adolescents aged $15-19$ years have ever had sexual intercourse before the age of 15 years, although this can vary across the countries [12].

Globally, the number of people living with HIV/AIDS is declining across all age groups: for instance, from 3.4 million in 1996 to 1.8 million in 2017 there was a decline from to, respectively [13]. However, SSA is the most affected region by HIV/AIDS accounting for over two-thirds of the daily global total new HIV infections [10]. There is evidence that $45 \%$ of the global new HIV infections occur in SSA, and 53\% of people living with HIV are from this region [13]. Adolescents aged 15-24 years have a higher rate of HIV infections and more than $50 \%$ of new infections $[11,12]$. About $70 \%$ of all global AIDS-related mortality occur in SSA [12] despite a decline in HIV incidence and mortality by 30 and $45 \%$ in the year 2010 and 2017, respectively [13]. In SSA, HIV/ AIDS is the leading cause of deaths among adolescents aged 10-19 years [14].

Young women and adolescent girls in SSA have a disproportionally high risk of HIV infections because of the existing gender-based violence, inequalities, and physiological factors [13]. Nevertheless, some of the countries in SSA have laws and policies which discourage the adolescent girls from acquiring parental consent in accessing sexual and reproductive health [13]. Moreover, the laws that govern the adolescents HIV testing varies across the countries of SSA [15]. World Health Organization (WHO), recommends HIV testing, counseling, and access to HIV services for all adolescents in high burden setting [16]. The recent studies in SSA, have reported the low prevalence of HIV testing among adolescents aged 15-19 years: 23 and 16\% among girls and boys, respectively $[17,18]$. In those studies, the following were among the challenges to HIV testing and counseling: legal and policy restricted age-of-consent to
HIV testing and counseling, difficult in accessing testing and counseling services, and fear of social stigma [17].

The findings from 18 HIV prevention studies showed that STIs is prevalent in SSA: higher among younger women (15-24-year-old) than older women (25-49-yearold). The average prevalence of gonorrhea for women aged 15-24 years, was found to range from $4.6 \%$ in South Africa to $8.2 \%$ in East Africa [19]. Moreover, the prevalence of at least one STI among HIV-infected adolescents aged 13-19 years was found to be $28 \%$ in Kenya [20] and $13.5 \%$ in Ethiopia [21]: females were more affected than male adolescents.

Adolescent pregnancy has significant adverse maternal and perinatal outcomes. The incidence of adolescent pregnancy is on the rise in low and middle-income countries (LMICs), including SSA [22]. In SSA, the proportion of adolescent pregnancy is highest with over 200 births per 1000 girls age 15-19 years [23]. The pooled prevalence of adolescent pregnancy from 52 studies was reported to be $18.8 \%$ for Africa and $19.3 \%$ for the SSA region. Poor parental-child communication on sexual and reproductive health was among the reported risk factor for adolescent pregnancy [24].

It is not uncommon to find a clustering of risktaking behaviors such as substance use: alcohol drinking, use of tobacco, marijuana, and amphetamines among adolescents [25]. In SSA, the co-occurrence of risk-taking behaviors such as the use of alcohol, tobacco, and illicit drugs are reported to drive more sexual intercourse behaviors among adolescents [2, $22,26]$. For instance, a study conducted in four countries of SSA revealed that adolescents who drink alcohol tend to have more than one sexual partner compared to their counterparts [27]. A school-based health survey in Kenya found that adolescents who engaged in sexual intercourse were more likely to use illicit drugs, drink alcohol, and smoke cigarettes [28]. Although risk-taking behaviors among adolescents may occur in clusters, they are easily forgotten by the programs that target only a single domain, for instance, reproductive health alone [2]. The singledomain approach may not be effective in tackling the global adolescent's health, given the clustering of sexual and non-sexual risk-taking behaviors. Therefore, multiple-domain prevention programs: an intervention that targets multiple risk behaviors concurrently may be needed. In SSA, there is limited information about the correlates between the clustering of non-sexual risk-taking behaviors and sexual intercourse behaviors among adolescents. Therefore, our current study sought to estimate the prevalence and correlates of sexual intercourse among in-school adolescents from five SSA countries. The purpose is to inform the public health programs dedicated to fighting HIV/AIDS. 


\section{Method}

\section{Data source}

We did a secondary analysis of the Global School-based Student Health Surveys (GSHS) datasets pooled from five SSA countries Benin, Mozambique, Namibia, Seychelles, and Tanzania. Our current analysis included a sample of 15,318 in-school adolescents. The primary independent variables were ever had sexual intercourse and sex with multiple partners, while the dependent variables were smoking cigarettes, alcohol use, use of marijuana and amphetamine, and parental connectedness. We performed descriptive statistics, and multivariate logistic regression stratified by gender using SPSS Complex Sample Statistics. A $p$-value of less than 0.05 was considered statistically significant at $95 \%$ confidence intervals.

We did a secondary analysis of the Global School-based Student Health Surveys (GSHS) datasets pooled from five SSA countries Benin, Mozambique, Namibia, Seychelles, and Tanzania. We purposely selected those countries from among other SSA countries because they did their surveys near the same year period 2013-2016. Moreover, each country included the question about sexual behaviors, substance use behaviors (cigarette smoking, alcohol drinking, use of marijuana and amphetamine) and parental connectedness in the survey. More details about the GSHS dataset files can be accessed through https:www.who.int/ ncds/surveillance/gshs/datasets/en/.

The GSHS is a self-administered, school-based survey developed by the WHO in collaboration with the United Nations Children Fund (UNICEF), the Joint United Nations Programme on HIV/AIDS (UNAIDS), and the United Nations Educational, Scientific and Cultural Organization (UNESCO). The financial and technical assistance was provided by the US Centre for Disease Control and Prevention (CDC). The purpose of GSHS is to collect data about risk-taking behaviors including sexual behaviors that contribute to HIV infection, other sexually transmitted infections, and unintended pregnancy from students aged 13 to 17 years [28].

\section{Sampling technique, data collection, and sample size}

The GSHS surveys used a two-stage cluster sampling to obtain a representative sample of students in each country. The first stage primary sampling units, schools were selected with a probability proportional to their enrolment size. The second stage involved a sampling of a systematic sample of classes in the selected schools. All students in the selected classes were eligible and invited to participate. Moreover, they were clearly explained that they are free not to participate or respond to any question in the questionnaire. Survey questions were translated into an appropriate language of instructions for the students and were pilot tested for comprehension. Students completed a self-administered questionnaire during one classroom period without personal identifiers. The current analysis used pooled data from Benin, Mozambique, Namibia, Seychelles, and Tanzania surveys administered during 2016, 2015, 2013, 2015, and 2014, respectively. A total of 15,318 students from the five countries completed the survey. For more details, see Additional file 1: Table S1.

\section{Measures of variables \\ Dependent variables}

The sexual intercourse variables were: (i) "Percentage of students who ever had sexual intercourse" The variable was dichotomized as Yes and No. (ii)“ Percentage of students who had sexual intercourse with two or more persons (during their life)" The variable was dichotomized as Yes and No.

\section{Independent variables}

Substance use variables: (i) Currently smoked cigarettes: "During the past 30 days, on how many days did you smoke cigarettes? The variable was dichotomized as "0 days" and " $1 \geq$ day". (ii) Currently drank alcohol: "During the past 30 days, on how many days did you have at least one drink containing alcohol? The variable was dichotomized as " 0 days" and " $1 \geq$ day". (iii) Currently used Marijuana (cannabis): "During the past 30 days, how many times have you used marijuana? The variable was dichotomized as " 0 days" and " $1 \geq$ day". (iv) use of amphetamine/methamphetamine: "During your life, how many times have you used amphetamines or methamphetamines (also known as stimulants not prescribed by a doctor)?" The variable was dichotomized as "0 days" and " $1 \geq$ day".

Parental connectedness: For the purpose of the current study it is defined as how often the parents or guardians understand the problems or worries of their children. The students were asked: "During the past 30 days, how often did your parents or guardians understand your problems or worries?" The variable was dichotomized as "sometimes to always" and "never or rarely".

We also included sociodemographic variable; gender dichotomized as male and female, age, and class grades (grade 6 to 12 ).

\section{Data process and analysis}

We considered the appropriateness of combining the GSHS datasets across the five countries, including sampling design and error and non-sampling error. Previous studies have shown that combining country-based survey data to regional estimate is realistic [29]. The sampling design was similar across the selected countries, and participants within each country were done at two levels: school and class. Non-sampling errors were examined using survey overall response rates, ranged from $78 \%$ (Benin) to $89 \%$ (Namibia): see Additional file 1: 
Table S1. Following the above consideration, we pooled the data from the five countries GSHS datasets.

The GSHS dataset has missing data as a result of nonresponses. We observed that the data were missing at random pattern. Therefore, we used multiple imputations [30-32] to examine a possibility of bias between findings of the imputed dataset and that of the original dataset. We found that there were no differences in outcomes of interest when we replaced the missing data with imputed data. Therefore, a significant measure of association in both the bivariate and multivariate analyses was maintained despite imputation. We run a maximum of five imputations to allow for $>97 \%$ efficiency. Different studies elsewhere have applied multiple imputations technique to account for missing data [33-37].

Our current analysis used a Complex Samples Statistics command of SPSS version 22 because of the complex sampling design nature of the GSHS. We used a chi-square $x^{2}$ to compare the differences between the categorical variables, and a multivariate logistic regression stratified by gender to explain the association between independent and dependent variables. Each of the variables in the model was adjusted for the rest of all other variables. The category age was analyzed as a continuous variable. A $p$-value of less than 0.05 was considered statistically significant at $95 \%$ confidence intervals.

\section{Results}

Table 1 represents the prevalence of sexual and nonsexual risk-taking behaviors among in-school adolescents stratified by gender.

Of the 15,318 participants, the overall prevalence of ever had sexual intercourse and sex with multiple partners were $43.5 \%$ (6670) and 20.9\% (3204), respectively. In overall and across each country, male adolescents had a significantly higher proportion of sex with multiple partners than female adolescents.

Table 2 represents multivariate logistic regression for predictors of sexual intercourse and sex with multiple partners among in-school adolescents.

For both genders, the predictors of sexual intercourse with multiple partners were currently smoked cigarette, currently drank alcohol, and currently used marijuana. Female adolescents who currently smoked cigarettes and used marijuana had a significant likelihood of sex with multiple partners than male adolescents: [aOR 3.6, 95\% CI: 2.6-5.1] vs [aOR 2.1, 95\% CI: 1.7-2.7] and [aOR 2.4, 95\% CI: 1.6-3.7] vs [aOR 1.9, 95\% CI: 1.3-2.7], respectively. Only female adolescents with parental connectedness were significantly less likely to have sex with multiple partners.

\section{Discussion}

In our current study, we estimated the prevalence of sexual intercourse and sex with multiple partners and examined their correlates with substance use among inschool adolescents. We used a representative sample size of the GSHS pooled from the five SSA countries.

Our study found that about half of the adolescents reported having engaged in sexual intercourse. More importantly, we found that about one-fourth of adolescents have ever involved in sexual intercourse with multiple partners. Previous studies in SSA have found a comparable prevalence of sex with multiple partners among adolescents, but with variation across the countries [38]. Unprotected and early age at sexual intercourse and more especially sex with multiple partners carries a high risk of acquiring HIV infections, other STIs, and teenage pregnancy [5-9]. Multiple sexual partner's relationships behaviors create a network that drives HIV transmission and the majority of STIs in the general population [39]. The low use of condom is among the factors for the high prevalence of unprotected sexual intercourse among young adults and more especially adolescents [40]. Discussion about sexual health is sensitive, and an embarrassing for adolescents because they are still learning and negotiating to adapt and maintain the intimate relationship at their very first time in life [41, 42]. Also, teaching sexual health topics to adolescents may be incompatible with cultural norms, especially for adolescent girls who are not confident to disclose their sexual life ambitions, feelings, and preferences [42, 43]. Nevertheless, the immaturity of the prefrontal cortex in adolescents is associated with heightened impulsivity and inability to have a wise plan or forecast the consequences of risk-taking behaviors [44]. In some studies, more than $50 \%$ of adolescents had never discussed with their sexual partner about safer sex, including condom use [45-47]. About two-thirds of HIV/AIDS-related infections and mortality in the world occur in SSA [12], and adolescents and young adults comprise more than one-third of its total population (49). Therefore, the high prevalence of sexual intercourse and especially sex with multiple partners among adolescents may continue to drive HIV/AIDS pandemic in this region if we don't take quick measures regarding the adolescent's sexual health policy.

Furthermore, our current study has provided evidence of some similarities between the five countries regarding the prevalence of sexual intercourse behaviors among adolescents. Except for Tanzania, there were relatively small differences in the study findings across the countries because of differences in the socio-economic structure, cultural, political, legal, and religious domains. For instance, teaching or discussions about sexual and reproductive health may be incompatible with cultural norms in some countries especially for adolescent girls who have limited social interaction and less confidence to disclose their sexual ambitions $[41,48]$. 
Table 1 Prevalence of sexual and non-sexual risk-taking behaviors among in-school adolescents stratified by gender

\begin{tabular}{|c|c|c|c|c|c|c|}
\hline \multirow[t]{2}{*}{ Country } & \multirow[t]{2}{*}{ Variables } & & \multirow[t]{2}{*}{ Total $n(\%)$} & \multicolumn{2}{|l|}{ Gender } & \multirow[t]{2}{*}{$P$-value } \\
\hline & & & & Male $n(\%)$ & Female $n(\%)$ & \\
\hline \multirow[t]{7}{*}{ Benin $(n=2536)$} & Ever had sexual intercourse & Yes & $1215(47.9)$ & $799(31.5)$ & $416(16.4)$ & $<0.001$ \\
\hline & Sex with multiple partners & Yes & $650(25 \cdot 6)$ & $541(21.3)$ & $109(4.3)$ & $<0.001$ \\
\hline & Currently smoked cigarettes & Yes & $109(4.3)$ & $87(3.4)$ & $22(0.9)$ & $<0.001$ \\
\hline & Currently drank alcohol & Yes & $1015(40.0)$ & $593(23.4)$ & $422(16.6)$ & 0.003 \\
\hline & Currently used marijuana & Yes & $24(0.9)$ & $20(0.8)$ & $4(0.1)$ & 0.005 \\
\hline & Ever used amphetamine & Yes & $49(1.9)$ & $37(1.5)$ & $12(0.4)$ & 0.002 \\
\hline & Parental connectedness & Yes & $835(32.9)$ & $438(17.3)$ & $397(15.6)$ & 0.23 \\
\hline \multirow[t]{7}{*}{ Mozambique $(n=1918)$} & Ever had sexual intercourse & Yes & $1149(59.9)$ & $706(36.8)$ & $443(23.1)$ & $<0.001$ \\
\hline & Sex with multiple partners & Yes & $544(28.4)$ & $411(21.4)$ & $133(7.0)$ & $<0.001$ \\
\hline & Currently smoked cigarettes & Yes & $55(2.8)$ & $34(1.7)$ & $21(1.1)$ & 0.46 \\
\hline & Currently drank alcohol & Yes & $263(13.7)$ & $145(7.6)$ & $118(6.1)$ & 0.57 \\
\hline & Currently used marijuana & Yes & $30(1.6)$ & $23(1.2)$ & $7(0.4)$ & 0.02 \\
\hline & Ever used amphetamine & Yes & $28(1.5)$ & $17(0.9)$ & $11(0.6)$ & 0.34 \\
\hline & Parental connectedness & Yes & $854(44.5)$ & $450(23.5)$ & $404(21.0)$ & 0.74 \\
\hline \multirow[t]{7}{*}{ Namibia $(n=4531)$} & Ever had sexual intercourse & Yes & $2416(53.3)$ & $1389(30.7)$ & $1027(22.6)$ & $<0.001$ \\
\hline & Sex with multiple partners & Yes & $1174(25.9)$ & $810(17.9)$ & $364(8.0)$ & $<0.001$ \\
\hline & Currently smoked cigarettes & Yes & $443(9.8)$ & $300(6.6)$ & $143(3.2)$ & $<0.001$ \\
\hline & Currently drank alcohol & Yes & $1476(32.6)$ & $823(18.2)$ & $653(14.4)$ & $<0.001$ \\
\hline & Currently used marijuana & Yes & $243(5.4)$ & $152(3.3)$ & $91(2.1)$ & $<0.001$ \\
\hline & Ever used amphetamine & Yes & $256(5.6)$ & $159(3.5)$ & $97(2.1)$ & $<0.001$ \\
\hline & Parental connectedness & Yes & $1852(40.9)$ & $841(18.6)$ & $1011(22.3)$ & 0.04 \\
\hline \multirow[t]{7}{*}{ Seychelles $(n=2540)$} & Ever had sexual intercourse & Yes & $1048(41.3)$ & $555(21.9)$ & $493(19.4)$ & $<0.001$ \\
\hline & Sex with multiple partners & Yes & $584(23.0)$ & $322(12.7)$ & $262(10.3)$ & 0.001 \\
\hline & Currently smoked cigarettes & Yes & $507(20.0)$ & $302(11.9)$ & $205(8.1)$ & $<0.001$ \\
\hline & Currently drank alcohol & Yes & $1177(46.3)$ & $549(21.6)$ & $628(24.7)$ & 0.55 \\
\hline & Currently used marijuana & Yes & $249(9.8)$ & $171(6.7)$ & $78(3.1)$ & $<0.001$ \\
\hline & Ever used amphetamine & Yes & $128(5.0)$ & $89(3.5)$ & $39(1.5)$ & $<0.001$ \\
\hline & Parental connectedness & Yes & $810(31.9)$ & $376(14.8)$ & $434(17.1)$ & 0.55 \\
\hline \multirow[t]{7}{*}{ Tanzania $(n=3793)$} & Ever had sexual intercourse & Yes & $842(22.2)$ & $529(13.9)$ & $313(8.3)$ & $<0.001$ \\
\hline & Sex with multiple partners & Yes & $252(6 \cdot 6)$ & $183(4.8)$ & $69(1.8)$ & $<0.001$ \\
\hline & Currently smoked cigarettes & Yes & $177(4.7)$ & $99(2.6)$ & $78(2.1)$ & 0.04 \\
\hline & Currently drank alcohol & Yes & $190(5.0)$ & $101(2.7)$ & $89(2.3)$ & 0.16 \\
\hline & Currently used marijuana & Yes & $100(2.6)$ & $51(1.3)$ & $49(1.3)$ & 0.99 \\
\hline & Ever used amphetamine & Yes & $118(3.1)$ & $55(1.4)$ & $63(1.7)$ & 0.56 \\
\hline & Parental connectedness & Yes & $1456(38.4)$ & $683(18.0)$ & $773(20.4)$ & 0.26 \\
\hline \multirow[t]{7}{*}{ Overall $(N=15,318)$} & Ever had sexual intercourse & Yes & $6670(43.5)$ & $3978(26.0)$ & $2692(17.5)$ & $<0.001$ \\
\hline & Sex with multiple partners & Yes & $3204(20 \cdot 9)$ & $2267(14.8)$ & $937(6.1)$ & $<0.001$ \\
\hline & Currently smoked cigarettes & Yes & $1291(8.4)$ & $822(5.3)$ & $469(3.1)$ & $<0.001$ \\
\hline & Currently drank alcohol & Yes & $4121(26.9)$ & $2211(14.4)$ & $1910(12.5)$ & $<0.001$ \\
\hline & Currently used marijuana & Yes & $646(4.2)$ & $417(2.7)$ & $229(1.5)$ & $<0.001$ \\
\hline & Ever used amphetamine & Yes & $579(3.7)$ & $357(2.3)$ & $222(1.4)$ & $<0.001$ \\
\hline & Parental connectedness & Yes & $5807(37.9)$ & $2788(18.2)$ & 3019 (19.7) & 0.01 \\
\hline
\end{tabular}


Table 2 Multivariate logistic regression for predictors of sexual intercourse and sex with multiple partners among in-school adolescents stratified by gender $(N=15,318)$

\begin{tabular}{|c|c|c|c|c|c|}
\hline \multirow[t]{2}{*}{ Variable } & \multirow[b]{2}{*}{ Gender } & \multicolumn{2}{|c|}{ Ever had sexual intercourse } & \multicolumn{2}{|c|}{ Sex with $\geq 2$ persons } \\
\hline & & OR $[95 \% \mathrm{Cl}]$ & $\mathrm{aOR}[95 \% \mathrm{Cl}]$ & $\mathrm{OR}[95 \% \mathrm{Cl}]$ & $\mathrm{aOR}[95 \% \mathrm{Cl}]$ \\
\hline \multicolumn{6}{|c|}{${ }^{a}$ Current smoked cigarette (No) } \\
\hline \multirow[t]{2}{*}{ Yes } & Male & $3.2[1 \cdot 7-6.2]^{* *}$ & $1.9[1.3-2.8]^{* *}$ & $3.2[2.7-3.9]^{* * *}$ & $2.1[1.7-2.7]^{* * *}$ \\
\hline & Female & $4.4[2 \cdot 7-7.3]^{* * *}$ & $3.0[2.2-4.2]^{* * *}$ & $6.3\left[4.7-8.6^{* * *}\right.$ & $3.6[2.6-5.1]^{* * *}$ \\
\hline \multicolumn{6}{|c|}{${ }^{a}$ Currently drank alcohol (No) } \\
\hline \multirow[t]{2}{*}{ Yes } & Male & $3.0[2.4-3.8]^{* * *}$ & $2 \cdot 1[1.8-2.4]^{* * *}$ & $3 \cdot 2[2 \cdot 7-3.9]^{* * *}$ & $2 \cdot 3[1.9-2 \cdot 7]^{* * *}$ \\
\hline & Female & $2.5[2.1-2.9]^{* * *}$ & $1.7[1.5-2.0]^{* * *}$ & $3 \cdot 4[2 \cdot 5-4.8]^{* * *}$ & $2 \cdot 2[1 \cdot 7-2 \cdot 9]^{* * *}$ \\
\hline \multicolumn{6}{|c|}{${ }^{a}$ Currently used marijuana (No) } \\
\hline \multirow[t]{2}{*}{ Yes } & Male & $5.8[1.3-26.5]^{*}$ & $2.2[0.9-5.7]$ & $3.6[2.8-4.8]^{* * *}$ & $1.9[1 \cdot 3-2 \cdot 7]^{* *}$ \\
\hline & Female & $6.2[1.9-19.9]^{*}$ & $1.9[0.8-4.5]$ & $7.7[5.8-10.1]^{* * *}$ & $2.4[1.6-3.7]^{* * *}$ \\
\hline \multicolumn{6}{|c|}{${ }^{a}$ Ever used amphetamine (No) } \\
\hline \multirow[t]{2}{*}{ Yes } & Male & $6 \cdot 8[1 \cdot 0-45.2]^{*}$ & $3.8[0.8-19.0]$ & $2.8[2.2-3.6]^{* * *}$ & $1 \cdot 3[1 \cdot 0-1.8]$ \\
\hline & Female & $7.2[1.9-26.7]^{*}$ & $4.1[1.4-12.6]^{*}$ & $5.6[4.2-7.6]^{* * *}$ & $1 \cdot 8[1 \cdot 1-2.9]^{*}$ \\
\hline \multicolumn{6}{|c|}{ aParental connectedness (No) } \\
\hline \multirow[t]{2}{*}{ Yes } & Male & $0.8[0.7-0.9]^{* *}$ & $0 \cdot 9[0.8-1.0]$ & $0 \cdot 9[0 \cdot 8-1.0]$ & $1.0[0.9-1.1]$ \\
\hline & Female & $0.7[0.6-0.8]^{* * *}$ & $0.7[0.7-0.8]^{* * *}$ & $0.6[0.5-0.8]^{* * *}$ & $0.7[0.6-0.9]^{* *}$ \\
\hline \multirow[t]{2}{*}{ Age } & Male & $1 \cdot 3[1.3-1.4]^{* * *}$ & $1.4[1.3-1.4]^{* * *}$ & $1 \cdot 4[1 \cdot 3-1 \cdot 5]^{* * *}$ & $1 \cdot 4[1 \cdot 3-1 \cdot 5]^{* * *}$ \\
\hline & Female & $1.4[1.3-1.4]^{* * *}$ & $1.4[1.4-1.5]^{* * *}$ & $1 \cdot 3[1 \cdot 2-1 \cdot 4]^{* * *}$ & $1.4[1 \cdot 2-1.5]^{* * *}$ \\
\hline
\end{tabular}

Note: $O R$ odds ratio, $a O R$ adjusted odds ratio

${ }^{*} P<0.05,{ }^{* *} P<0.01, * * * P<0.001$

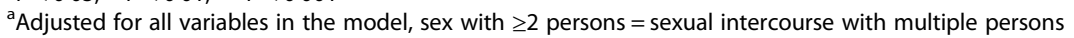

Moreover, the current study revealed that adolescents who engaged in sexual intercourse were more likely to have other risk-taking behaviors such as smoking cigarettes, alcohol use, and illicit drug use (marijuana and amphetamines). Adolescents are curious in exploring the unknown and venturing a number of risk-taking behaviors [42] including sexual intercourse and substance use. Therefore, the strong evidence of correlations between sexual intercourse and other risk-taking behaviors in our current study suggest the clustering of health risk-taking behaviors among adolescents. For instance, the adolescent who drinks alcohol or uses illicit drugs may have a sensation-seeking of other risk-behavior such as sexual intercourse. The correlation between the clustering of risk-taking behaviors such as substance use has been shown to drive the sexual intercourse behaviors among adolescents in SSA [27, 43].

We also found that female adolescents who had parental connectedness were significantly less likely to have had sexual intercourse or sex with multiple partners. Family communication and parental connectedness provide protection against risk-taking behaviors among adolescents (52). For instance, studies in SSA have reported that adolescents living with neither parent had a lower likelihood of delaying sexual intercourse [44]. Moreover, other studies have reported that adolescent from families with poor parental connectedness has increased the likelihood of involving in risk-taking behaviors [45-47]. The comparable findings from our current study suggest an independent role of parental connectedness as a social protective factor against sexual intercourse behaviors among adolescents and more especially female adolescents.

The current study has the following strength; although it was a cross-sectional study, we used appreciably large sample size pooled from five countries. Moreover, the finding gives valuable insight and scope of the association between sexual and non-sexual risk-taking behaviors in the region with the highest burden of HIV/AIDS. Therefore, our study informs the policymakers to oversee the policy and programs that target multiple domains regarding clustering of risk-taking behaviors among adolescents.

On the other hand, the current study should be interpreted with a consideration of the following possible limitations. First, the GSHS study involves in-school adolescents, therefore, the current finding, may not be generalized to include out-of-school adolescents. Outof-school adolescents may have relevant information regarding risk-taking behaviors. Therefore, current study findings cannot be generalized to all adolescents. Second, since the design of the study was cross-sectional, hence, this limits its utility to explain the relative proportion and temporal correlates of all explanatory 
factors of the sexual intercourse behaviors among adolescents. Third, since the survey was self-reported, it relied upon study participants recall memory hence leading to potential recall bias. Fourth, most of the study variables are based on a single item-response. Therefore, it could have unfairly reflected a complex concept behind the clustering of risk behaviors among adolescents. Fifth, social desirability could be another limitation of the current study. Most questions addressed undesirable and sensitive behavior like sexual intercourse. Adolescents could have responded less of sensitive questions, while responded more of questions that target good behaviours, hence, leading to response bias. Therefore, there could be a possibility of under-reporting sensitive or bad behaviors while over-reporting good behaviors. Although we used the principle of anonymity in the current study, still the issue of social desirability is indisputable.

\section{Conclusions}

Sexual intercourse and more especially sex with multiple partners were prevalent and strongly correlated with substance use among in-school adolescents in SSA. However, the correlation was higher among female adolescents than male adolescents. A customized public health intervention that targets multiple risk factors concurrently may benefit adolescents with clustering of sexual and non-sexual risktaking behaviors. Furthermore, parental connectedness may be an effective social promoting factor for sexual health among female adolescents.

\section{Supplementary information}

Supplementary information accompanies this paper at https://doi.org/10. 1186/s12889-019-7632-1.

Additional file 1: Table S1. Summary of sampling technique, data collection, and sample size of the Global School-based Students Health Survey of the five Sub Saharan Africa countries.

\section{Abbreviations \\ AIDS: Acquired Immune Deficiency Syndrome; aOR: Adjusted odds ratio; CDC: Centre for Diseases Control and Prevention (USA); COR: Crude odds ratio; GSHS: Global School-based Student Health Survey; HIV: Human Immunodeficiency Virus; SSA: Sub-Saharan Africa; UNAIDS: United Nations Programme on HIV/AIDS; UNESCO: United Nations Educational, Scientific and Cultural Organization; UNICEF: United Nations Children Fund; USA: United States of America; WHO: World Health Organization}

\section{Acknowledgments}

The authors would like to thank the country ministries and coordinators from Benin (Dr. Robert Franck ZANNOU), Mozambique (Mr. Augusto Nunes), Namibia (Ms. Aletta Noabes), Seychelles (Ms. Bharathi Viswanathan), and Tanzania (Dr. Ursuline S. Nyandindi) for their assistance in the collection of the Global School-based Student Health Survey data. Special thanks to the country ministries of Health and Education for their indisputable coordination of the survey. We gratefully acknowledge all students and individuals who voluntarily assented to participate in the Global School-based Student Health Survey. Also, we express our thanks to the World Health Organization and the Centre for Disease Control and Prevention (USA) for making the dataset available in the public domain for further analysis.

\section{Authors' contributions}

FKS developed a hypothesis, searched the literature, reviewed the relevant articles, analyzed the data, interpreted the findings, and wrote a manuscript. MHK developed the hypothesis, reviewed the relevant article, interpreted the findings, and wrote the manuscript. All authors have read and approved the manuscript.

\section{Funding}

No fund was provided for the current study analysis.

\section{Availability of data and materials}

The datasets files used for analysis in the current study are publicly free available in the WHO repository (https://www.who.int/ncds/surveillance/ gshs/datasets/en/).

\section{Ethics approval and consent to participate}

The present study was based on an analysis of the existing public domain of the five countries GSHS survey datasets that are freely available online with all identifier information detached. The GSHS surveys were approved by appropriate government agencies (e.g. ministries of education and health. Written assent was obtained from all students eligible to participate in the GSHS before filling the questionnaire. Students were invited to participate in the study and were clearly explained that they were free not to participate and also not to respond to any question on the questionnaire. Survey procedures were designed to protect student privacy by allowing for anonymous and voluntary participation. Therefore, the ethical approval for the current analysis was automatically deemed unnecessary.

\section{Consent for publication}

Not applicable for the current analysis.

\section{Competing interests}

The authors declare that they have no competing interests.

\section{Author details}

${ }^{1}$ Department of Internal Medicine, Muhimbili University of Health and Allied Sciences, P.O Box 65001, Dar es Salaam, Tanzania. '2Division of Public Health, Department of Global Health Entrepreneurship, Graduate School of Tokyo Medical and Dental University, 1-5-45 Yushima, Bunkyo-ku, Tokyo 113-8510, Japan. ${ }^{3}$ Department of Non Communicable Disease, Ministry of Health, Community Development, Gender, Elderly, and Children (MoHCDGEC), Dodoma, Tanzania.

Received: 4 February 2019 Accepted: 16 September 2019

Published online: 12 October 2019

\section{References}

1. Twa-Twa JM, Oketcho S, Siziya S, et al. Prevalence and correlates of condom use at last sexual intercourse among in-school adolescents in urban areas of Uganda. East Afr J Public Health. 2008;5:22-5.

2. Gambadauro P, Carli V, Hadlaczky G, et al. Correlates of sexual initiation among European adolescents. PLoS One. 2018;13:e0191451.

3. Cavazos-Rehg PA, Spitznagel EL, Bucholz KK, Nurnberger J, Edenberg HJ, Kramer JR, et al. Predictors of sexual debut at age 16 or younger. Arch Sex Behav. 2010;39(3):664-73.

4. Zuma K, Setswe G, Ketye T, Mzolo T, Rehle T, Mbelle N. Age at sexual debut: a determinant of multiple partnership among south African youth. Afr J Reprod Health. 2010;14(2):47-54.

5. Shrestha R, Karki P, Copenhaver M. Early sexual debut: a risk factor for STIs/ HIV acquisition among a nationally representative sample of adults in Nepal. J Community Health. 2016;41(1):70-7.

6. Ma Q, Ono-Kihara M, Cong L, Xu G, Pan X, Zamani S, et al. Early initiation of sexual activity: a risk factor for sexually transmitted diseases, HIV infection, and unwanted pregnancy among university students in China. BMC Public Health. 2009:9:1-8

7. Li J, Li S, Yan H, Xu D, Xiao H, Cao Y, et al. Early sex initiation and subsequent unsafe sexual behaviors and sex-related risks among female undergraduates in Wuhan, China. Asia-Pacific J Public Heal. 2015;27:21S-9S.

8. Magnusson BM, Masho SW, Lapane KL. Early age at first intercourse and subsequent gaps in contraceptive use. J Women's Heal. 2011;21(1):73-9. 
9. Noel J, Geary CW, Tucker H, Wedderburn M, Noel BJ, Waszak C, et al. The Influence of Early Sexual Debut and Sexual Violence on Adolescent Pregnancy: A Matched The Influence of Early Sexual Debut and Sexual Violence On Adolescent Pregnancy : A Matched Case-Control Study In Jamaica contraception. 2012;35(1).

10. World Health Organization (WHO): HIV_AIDS fact sheet. http://www.who.int/ news-room/fact-sheets/detail/hiv-aids. Accessed 8 Jan 2019

11. Wilson CM, Wright PF, Safrit JT, Rudy B. Epidemiology of HIV infection and risk in adolescents and youth. JAIDS J Acquir Immune Defic Syndr. 2010 Jul; 54(SUPPL. 1):S5-6.

12. Kharsany ABM, Karim QA. HIV infection and AIDS in sub-Saharan Africa: current status, Challenges and Opportunities. Open AIDS J. 2016;10(1):34-48.

13. The Joint United Nations Programme on HIV/AIDS (UNSAIDS). Program HIV/ AIDS. 2018;1-376.

14. UNICEF's Global HIV Response: Addressing the global HIV epidemic among pregnant women, Mothers, Children and Adolescents. 2018.

15. Armstrong A, Baggaley R, Ferguson J, Van Der Kwaak A, Wolmarans L. The voices, Values and Preference of Adolescents on HIV Testing and Counselling Consultation for the Development of the World Health Organization HIV Testing and Counselling Guidelines for Adolescents Commissioned by The World Health Organization-Departme; 2013. p. 1-67.

16. World Health Organization (WHO). HIV and adolescents: guidance for HIV testing and counselling and care for adolescents living with HIV: recommendations for a public health approach and considerations for policy-makers and managers. 2013.

17. McKinnon B, Vandermorris A. National age-of-consent laws and adolescent HIV testing in sub-saharan Africa: a propensity-score matched study. Bull World Health Organ. 2019;97(1):42-50.

18. United Nations Children's Fund. For every child, end AIDS - seventh stocktaking report. New York: UNICEF; 2016

19. Torrone EA, Morrison CS, Chen PL, Kwok C, Francis SC, Hayes RJ, et al. Erratum: Correction: Prevalence of sexually transmitted infections and bacterial vaginosis among women in sub-Saharan Africa: An individual participant data meta-analysis of 18 HIV prevention studies (PLoS medicine (2018) 152 (e1002511)). Vol. 15, PLoS medicine. 2018. e1002608 p.

20. Winston SE, Chirchir AK, Muthoni LN, Ayuku D, Koech J, Nyandiko W, et al. Prevalence of sexually transmitted infections including HIV in street-connected adolescents in western Kenya. Sex Transm Infect. 2015;91 (5):353-9.

21. Taffa N, Bjune G, Sundby J, Gaustad P. Risk behavior among youth in Addis Ababa, Ethiopia. Sex Transm Infect. 2002;29:828-33.

22. Lam T, Stewart SM, Ho L. Prevalence and correlates of smoking and sexual activity among Hong Kong adolescents. J Adolesc Health. 2001; 29(5):352-8.

23. United Nations Children's Funds (UNICEF): Adolescent health - UNICEF data. 2018. Accessed on 23 May 2019.

24. Kassa GM, Arowojolu AO, Odukogbe AA, Yalew AW. Prevalence and determinants of adolescent pregnancy in Africa: a systematic review and meta-analysis. Reprod Health. 2018;15(1):1-17.

25. de Looze M, ter Bogt TFM, Raaijmakers QAW, Pickett W, Kuntsche E, Vollebergh WAM. Cross-national evidence for the clustering and psychosocial correlates of adolescent risk behaviours in 27 countries. Eur J Pub Health. 2015;25(1):50-6.

26. Rudatsikira E, Ogwell AE, Siziya S, Muula AS. Prevalence of sexual intercourse among school-going adolescents in Coast Province, Kenya. Tanzan J Health Res. 2008:9(3):159-63.

27. John-langba J, Ezeh A, Guiella G, Kumi-Kyereme A, Neema S. Alcohol, drug Use, and sexual-risk behaviors among adolescents in four Sub-Saharan African Countries; 2003. p. 5-8.

28. Centro para el Control y Prevención de Enfermedades. Encuesta de salud estudiantil global basada en la escuela (GSHS). Published Online First: 2013.

29. Brown DW, Riley L, Butchart A, Kann L. Bullying among youth from eight African countries and associations with adverse health behaviors. Ped Health. 2008;2(3):289-99.

30. Rubin DB. An Overview of Multiple Imputation. In Proceedings of the Survey Research Section, American Statistical Association. 1988. p. 79-84.

31. Rubin DB. Multiple imputation for nonresponse in surveys (Wiley series in probability and statistics); 1987.

32. Howell D. Treatment of missing data. 2014.

33. Romo ML, Kelvin EA. Impact of bullying victimization on suicide and negative health behaviors among adolescents in Latin America. Rev Panam Salud Publica/Pan Am J Public Heal. 2016;40:347-55.
34. Azeredo CM, Levy RB, Peres MFT, Menezes PR, Araya R. Patterns of healthrelated behaviours among adolescents: a cross-sectional study based on the National Survey of School Health Brazil 2012. BMJ Open. 2016;6:e011571.

35. Randall JR, Doku D, Wilson ML, Peltzer K. Suicidal behaviour and related risk factors among school-aged youth in the republic of Benin. PLoS One. 2014;9(2):1-9.

36. Shayo FK. Co-occurrence of risk factors for non-communicable diseases among in-school adolescents in Tanzania: an example of a low-income setting of sub-Saharan Africa for adolescence health policy actions. BMC Public Health. 2019;19(1):972.

37. Shayo FK, Lawala PS. Does food insecurity link to suicidal behaviors among in-school adolescents? Findings from the low-income country of subSaharan Africa. BMC Psychiatry. 2019;19(1):1-8

38. Doyle AM, Mavedzenge SN, Plummer ML, Ross DA. The sexual behaviour of adolescents in sub-Saharan Africa: patterns and trends from national surveys. Trop Med Int Heal. 2012;17(7):796-807.

39. The Joint United Nations Programme on HIV/AIDS (UNSAIDS): Practical Guidelines for Intensifying HIV Prevention Uniting the world against AIDS. 2007.

40. Wilson Chialepeh N, Sathiyasusuman A. Associated risk factors of stis and multiple sexual relationships among youths in Malawi. PLoS One. 2015;10(8):1-13.

41. Widman L, Noar SM, Choukas-Bradley S, Francis DB. Adolescent sexual health communication and condom use: a meta-analysis. Health Psychol. 2014:33(10):1113-24. https://doi.org/10.1037/hea0000112.

42. Borracci RA, Borracci Andrés H Mulassi RA. El consumo de tabaco en la adolescencia puede predecir el tabaquismo durante la adultez: investigación basada en modelos de simulación. Arch Argent Pediatr. 2015;113(2):106-13.

43. Rudatsikira E, Ogwell AE, Siziya S, Muula AS. Prevalence of sexual intercourse among school-going adolescents in Coast Province, Kenya. Tanzan J Health Res. 2011;9(3):159-63.

44. Somefun OD, Odimegwu C. The protective role of family structure for adolescent development in sub-Saharan Africa. PLoS One. 2018;13(10):1-15.

45. Malta DC, Porto DL, Melo FCM, Monteiro RA, Sardinha LMV, Lessa BH. Family and the protection from use of tobacco, alcohol, and drugs in adolescents National Escolares 2011:14(3):166-177.

46. So ES, Yeo JY. Factors associated with early smoking initiation among Korean adolescents. Asian Nurs Res. 2015:9(2):115-9.

47. Lim KH, Lim HL, Teh CH, et al. Smoking among school-going adolescents in selected secondary schools in peninsular Malaysia- findings from the Malaysian adolescent health risk behaviour (MyaHRB) study. Tob Induc Dis. 2017;15:9. https://doi.org/10.1186/s12971-016-0108-5.

48. Lear D. Sexual communication in the age of AIDS: the construction of risk and trust among young adults. Soc Sci Med. 1995;41(9):1311-23.

\section{Publisher's Note}

Springer Nature remains neutral with regard to jurisdictional claims in published maps and institutional affiliations.

Ready to submit your research? Choose BMC and benefit from:

- fast, convenient online submission

- thorough peer review by experienced researchers in your field

- rapid publication on acceptance

- support for research data, including large and complex data types

- gold Open Access which fosters wider collaboration and increased citations

- maximum visibility for your research: over $100 \mathrm{M}$ website views per year

At BMC, research is always in progress.

Learn more biomedcentral.com/submissions 